\title{
13
}

\section{In the Eye of the Storm: Students' Perceptions of Helpful Faculty Actions Following a Collective Tragedy}

Therese A. Huston

Seattle University

Michele DiPietro

Carnegie Mellon University

On occasion, our campus communities are shaken by national tragedies such as Hurricane Katrina and the terrorist attacks of September 11, 2001, or by local tragedies such as the murder of a faculty member or student. Because these are unusual circumstances, faculty are often initially confused about how to respond, and later have little or no sense of how effective their actions have been (DiPietro, 2003). This chapter investigates the most common instructor responses following a tragedy and which of those responses students find most helpful. Implications for faculty and faculty developers are discussed.

C ampus communities deal with tragedy on both the national and local level. In the past decade, students and faculty across the country have struggled with the implications of the destruction brought about by Hurricane Katrina, the $9 / 11$ terrorist attacks, the Columbine shootings, and Matthew Shepard's brutal beating and death. Even though these events were geographically localized, their impact has been far-reaching. In particular, following Hurricane Katrina, students from the affected colleges and universities were relocated in institutions across all 50 states, generating unpredicted ripples in campus dynamics everywhere (Mangan, 2005). There are also local tragedies that receive less national attention but still leave faculty, staff, and 
students feeling frightened, angry, and vulnerable. For example, in fall 2002, a student at the University of Arizona-Tucson killed three professors in the nursing school with an automatic weapon before killing himself (Rooney, 2002). Another disturbing example occurred at Gallaudet University, where two students were murdered in the same dormitory within a period of a few months (Guterman, 2001). Sadly, these are only a few of the violent losses that campuses have faced in recent years.

Tragedies and disasters have a strong emotional and cognitive impact on students, even if the students are not directly affected by the catastrophe (Honos-Webb, Sunwolf, Hart, \& Scalise, 2006; Silver, Holman, McIntosh, Poulin, \& Gil-Rivas, 2002). Many students in the Boston area, for example, who were not directly impacted by the $9 / 11$ terrorist attacks, were nonetheless severely affected psychologically for two months or more following the attacks (Liverant, Hofmann, \& Litz, 2004). Recognizing the distress caused by natural and man-made disasters, the American Psychiatric Association (n.d.) has provided mental health guidelines to help college students deal with the loss and disruption caused by such tragedies.

Given the widespread impact of such tragedies, how do most campuses respond? Many college and university administrations have created crisis response teams, either in anticipation of or in response to a collective tragedy (Asmussen \& Creswell, 1995; Farrell, 2001). Campus officials also increase support for the members of their community; many schools issue campuswide policies to give everyone time to grieve, and university officials often create venues for students, faculty, and staff to learn more about the threatening events or to cope with heightened stress levels (e.g., Hurst, 1999). Administrators also have access to published guidelines on how to prepare a crisis response team, itemized lists of things to say and do immediately following a security threat, and recommendations for ensuring prompt and effective communication (Larson, 1994; Paine \& Sprague, 2000; Whiting, Tucker, \& Whaley, 2004).

Although administrators have benchmarks to follow before, during, and after a crisis, faculty members receive precious little guidance as to what to say or do in their classrooms. As a noteworthy exception, the Center for Research on Teaching and Learning at the University of Michigan (2004) has consistently assumed a leadership role on this issue by providing timely guidelines for discussions of Hurricane Katrina, the December 2004 tsunami, the war on Iraq, and $9 / 11$ on the "Publications and Links" page of their web site. Other exceptions we uncovered include the Faculty Center for Excellence in Teaching at Western Kentucky University (2000), which produced a booklet of short papers and reports on "Teaching and Learning in a Time of Crisis," and 
Michigan State University Libraries (2005), which compiled a list of resources for doing research on hurricanes as a way to address the Katrina crisis as a course project.

Given that faculty represent the arm of the campus community that has the most day-to-day student contact, it is crucial that they receive the tools to best support students in the context of their classes. This includes deciding whether to address the tragic events, and if so, knowing some different ways to do so and the comparative value of those options.

The crisis literature for administrators does not define which events constitute a crisis warranting a response from the administration. It only advises that the crisis management plans be as flexible as possible to include emergencies as diverse as crimes, natural disasters, suicide, plant failures, riots, bomb threats, disease, and scandals, among others (Larson 1994; Siegel 1994).

In the same vein, we too resist an inevitably narrow treatment of tragic events. Instead, this chapter reports the results of a study designed to categorize instructor responses, or lack thereof, following one specific crisis, the terrorist attacks of September 11,2001. The survey asked students to identify how their instructors responded to the attacks and to evaluate the usefulness of those actions. Even though the survey refers to a specific event, all the strategies listed and collected generalize to other catastrophes, so that the insights from this research are widely applicable.

\section{Literature Review}

Clinical researchers have examined psychological interventions to help people cope with the events of $9 / 11$, but their reports have focused on recommendations for psychologists and mental health professionals. For example, one study found that college students who participated in a journal writing exercise or who listened to a story that addressed themes relevant to the terrorist attacks showed greater improvements and fewer signs of trauma than a control condition (Honos-Webb et al., 2006). Another study found that adults who took an active approach, such as getting involved in their community efforts to help others, felt less distressed by the attacks (Silver et al., 2002).

Few researchers, however, have directly examined faculty responses to a national crisis, and the only relevant research we were able to uncover was a faculty survey developed by DiPietro (2003). Faculty were asked to report what, if anything, they had done in class after the $9 / 11$ attacks, the rationale for their response, and their perceptions of effectiveness. Three main themes emerged from that investigation. 
- Faculty responded in many different ways. Even in this high-end, self-selected sample, where most people were eager to share what they had done, a number of instructors (11\%) admitted that they did not address the attacks in class. When faculty did address the attacks directly, their responses ranged from quick, low-effort strategies (e.g., a minute of silence) to more lengthy, involved responses (e.g., incorporating the tragedy into the course topics or the final project).

- There was a general sense of confusion; some instructors were unsure about what their role should be. Other instructors, even though they felt a strong need to do something, were confused about what would be appropriate or advisable and, as a result, did nothing. Men and international instructors reported the most confusion.

- Some confusion persisted after the fact. Several instructors had no idea whether their actions had any impact. Likewise, some instructors who did nothing reported that even though it seemed like the best thing to do at the time (to foster a sense of normalcy), they later had no idea if that was indeed the best course of action.

These findings clearly reveal that faculty members need to be equipped with appropriate pedagogical tools, well in advance of tragic events.

\section{Method}

\section{Sample}

A sample of 2,000 students from a private, medium-size university was selected from the enrollment database by randomly generating the names of 400 students from each of the following five groups: first-year students, sophomores, juniors, seniors, and master's/Ph.D. students. Students completed the online survey voluntarily and were offered a lottery incentive: Two randomly drawn respondents from each group won a $\$ 50$ gift certificate toward purchases on Amazon.com.

\section{Instrument}

The survey was an online adaptation of an instructor survey (DiPietro, 2003), and most questions were simply modified to address students' perspectives. For instance, the original question "How many academic classes were you teaching in September 2001 ?" was changed to "How many academic classes were you taking in September 2001?" 
We administered the online survey using SurveyMonkey, a survey administration and data collection service. The survey included nine questions about demographics and academics, the last of which asked how many courses the student was taking in September 2001. For each course, the respondent answered six questions concerning the instructor-led activities following September 11 (see Appendix 13.1 for the complete survey).

\section{1: Procedure}

Each student received a brief email message in March 2002 inviting him or her to participate. The initial invitation included a link that took respondents to the online consent form. The software monitored which students had completed the survey to ensure that they could only complete the survey once. Two names were randomly drawn from each class for the online gift certificates, and prizes were awarded via email.

The results were calculated in terms of the number of reports (e.g., the number of reports in which faculty teaching labs offered extensions, led discussions, etc.). Helpfulness was only coded for the first two courses that each student reported because incrementally fewer and fewer students ranked the helpfulness of their third, fourth, and fifth courses.

\section{Results and Discussion}

Respondents

A total of 484 respondents ( $24.2 \%$ of the original 2,000 students in the sample) completed the survey. Table 13.1 provides a breakdown of respondents by gender, year in school, and academic discipline. An equal number of men and women completed the survey, but this was surprising because the student body at this institution for the 2001-2002 academic year was 65\% male and $35 \%$ female. Either females were over-represented in the original sample of 2,000 students, or a greater proportion of females were interested in the survey or the lottery prize. Table 13.1 also shows the proportion of respondents by academic discipline. Overall, the response rates were representative of the relative distribution of students across schools. For example, the engineering school had the highest response rate $(26.4 \%)$, but engineering is also the largest school at the institution, with $23.6 \%$ of all students in 2001-2002. In summary, the survey data represent first-year students through graduate students, a variety of academic disciplines, and equal numbers of men and women. 
TABLE 13.1

Demographic Characteristics of Participants ( $N=484$ )

\begin{tabular}{|l|c|c|}
\hline Gender & $\mathbf{n}$ & $\%$ \\
\hline Male & 243 & $50 \%$ \\
\hline Female & 242 & $50 \%$ \\
\hline Year in School & & \\
\hline First year & 123 & $25 \%$ \\
\hline Sophomore & 116 & $24 \%$ \\
\hline Junior & 82 & $17 \%$ \\
\hline Senior & 90 & $19 \%$ \\
\hline Master's or Ph.D. & 73 & $15 \%$ \\
\hline Academic Discipline & 85 & $18 \%$ \\
\hline Fine arts & 128 & $26 \%$ \\
\hline Engineering & 106 & $22 \%$ \\
\hline Sciences and computer science & 90 & $19 \%$ \\
\hline Humanities and social sciences & 69 & $14 \%$ \\
\hline Business and public policy & 6 & $1 \%$ \\
\hline Other* & & \\
\hline
\end{tabular}

* Includes enrolled students who had not yet declared their majors or students who were taking classes but were not working toward a specified degree.

\section{Responses to the Attacks}

Courses where the attacks were addressed. Students reported taking an average of 4.43 classes on September 11,2001, ranging from one class to five classes, with a median of five classes. As shown in the first row of Table 13.2, the majority of the reports came from small lecture ( $<50$ students), large lecture ( $>=50$ students), and discussion classes.

According to the students, only $62 \%$ of their instructors addressed the attacks, and the remaining $38 \%$ of their instructors failed to mention the attacks in class at all. Students indicated that faculty were more likely to mention the attacks in some types of courses than others: most frequently in discussion and studio courses (in $78 \%$ of discussion courses and $73 \%$ of studios) and least frequently in large lecture and project classes (53\% and 46\%, respectively). 
It is not surprising that the terrorist attacks were addressed more frequently in discussion and studio courses, where enrollments are typically smaller and classes are usually structured with a relatively high degree of faculty-student interaction. Using the same reasoning, one might have predicted that faculty would be less likely to mention the attacks in lecture halls with 50 students or more because faculty are less likely to know their students (particularly in the second week of classes, which is when the tragedy occurred for this campus). Faculty in large lectures may also have experienced more confusion about their roles with respect to the attacks, and DiPietro (2003) found that faculty who felt confused often said nothing about the attacks.

The fact that the attacks were mentioned least frequently in project courses was surprising because students usually receive individualized faculty attention around a group or individual project in such courses. One would predict a relatively high level of faculty-student interaction, much like discussion or studio courses. The project courses reported in this survey, however, varied dramatically in size, ranging from very small courses (i.e., one student in a drama thesis course) to relatively large team-based courses (i.e., an information systems course with more than 80 students). The size of the course could predict whether instructors addressed the attacks. It could also be that faculty (and perhaps students) in project courses were more focused on a specific product or outcome, so the tendency might have been to "get back to work" rather than linger on the terrorist attacks.

Fortunately, only eight students ( $1.7 \%)$ reported that none of their instructors addressed the terrorist attacks. Five of these students were freshmen or sophomores taking four to five classes each, predominantly in science, mathematics, and business.

Frequency of responses. When faculty addressed the terrorist attacks, what kinds of comments did they make, and what kinds of activities did they lead? The survey provided 14 possible responses based on DiPietro's (2003) faculty survey. Table 13.2 presents the frequency of responses organized by different types of courses. Students reported that the most common response (Response A, $31 \%$ of the instructors) was to communicate a two-part messagethat the class needed to go on with the material despite the attacks but there would be additional opportunities to review the material down the road. The second most common response (Response E, 23\%) was to excuse students from class or to offer an extension on an assignment. Faculty who addressed the attacks in class typically addressed them in multiple ways, so the total for each column in Table 13.2 exceeds $100 \%$. For example, faculty who asked if family and friends were affected (Response $M$ ) were also likely to lead a brief discussion in class (Response $\mathrm{G}$ ). 
TABLE 13.2

Types of Instructor Responses Across Different Types of Courses

\begin{tabular}{|c|c|c|c|c|c|c|c|}
\hline $\begin{array}{l}\text { Instructor } \\
\text { Response }\end{array}$ & $\begin{array}{c}\text { Discussion } \\
\mathrm{N}=342\end{array}$ & $\begin{array}{c}\text { Small } \\
\text { Lecture } \\
\mathrm{N}=338\end{array}$ & $\begin{array}{c}\text { Large } \\
\text { Lecture } \\
N=674\end{array}$ & $\begin{array}{c}\text { Lab } \\
N=81\end{array}$ & $\begin{array}{c}\text { Studio } \\
\mathrm{N}=157\end{array}$ & $\begin{array}{l}\text { Project } \\
\mathrm{N}=87\end{array}$ & $\begin{array}{c}\text { Total } \\
N=1679\end{array}$ \\
\hline No Response & $22 \%$ & $38 \%$ & $47 \%$ & $37 \%$ & $27 \%$ & $54 \%$ & $38 \%$ \\
\hline \multicolumn{8}{|c|}{ Types of Responses } \\
\hline A & $38 \%$ & $31 \%$ & $26 \%$ & $36 \%$ & $46 \%$ & $18 \%$ & $31 \%$ \\
\hline B & $13 \%$ & $13 \%$ & $15 \%$ & $15 \%$ & $9 \%$ & $9 \%$ & $13 \%$ \\
\hline $\mathrm{C}$ & $5 \%$ & $5 \%$ & $5 \%$ & $4 \%$ & $8 \%$ & $2 \%$ & $5 \%$ \\
\hline $\mathrm{D}$ & $12 \%$ & $12 \%$ & $9 \%$ & $12 \%$ & $23 \%$ & $5 \%$ & $11 \%$ \\
\hline$E$ & $20 \%$ & $24 \%$ & $22 \%$ & $25 \%$ & $32 \%$ & $13 \%$ & $23 \%$ \\
\hline $\bar{F}$ & $14 \%$ & $14 \%$ & $9 \%$ & $12 \%$ & $25 \%$ & $8 \%$ & $13 \%$ \\
\hline$G$ & $24 \%$ & $22 \%$ & $14 \%$ & $14 \%$ & $49 \%$ & $7 \%$ & $20 \%$ \\
\hline $\mathrm{H}$ & $12 \%$ & $11 \%$ & $6 \%$ & $5 \%$ & $17 \%$ & $8 \%$ & $10 \%$ \\
\hline I & $10 \%$ & $11 \%$ & $8 \%$ & $6 \%$ & $11 \%$ & $6 \%$ & $9 \%$ \\
\hline$J$ & $1 \%$ & $1 \%$ & $0 \%$ & $1 \%$ & $2 \%$ & $1 \%$ & $1 \%$ \\
\hline $\mathrm{K}$ & $2 \%$ & $1 \%$ & $1 \%$ & $0 \%$ & $1 \%$ & $0 \%$ & $2 \%$ \\
\hline $\mathrm{L}$ & $12 \%$ & $7 \%$ & $6 \%$ & $5 \%$ & $13 \%$ & $5 \%$ & $8 \%$ \\
\hline$M$ & $35 \%$ & $17 \%$ & $8 \%$ & $10 \%$ & $36 \%$ & $23 \%$ & $19 \%$ \\
\hline $\mathrm{N}$ & $6 \%$ & $4 \%$ & $3 \%$ & $5 \%$ & $4 \%$ & $3 \%$ & $5 \%$ \\
\hline
\end{tabular}

Key to Instructor Responses

A) Acknowledged that the class needs to go on with the material but reassured the class that if students were too distressed to process the material that there would be other opportunities to review it down the road

B) Acknowledged that the attacks had occurred and said that the class needs to go on, with no mention of opportunities for review or extra help

C) One minute of silence

D) Mentioned counseling services

E) Excused students/offered extensions if assignments were due

F) Offered to talk privately with anyone who might want to

G) Had a brief discussion in class

H) Devoted the whole first class after the attacks to discussion

I) Incorporated the event into the lesson plan/curriculum

J) Decided to do a project as a class (i.e., quilt, fence painting, etc.)

K) Read a passage from an inspirational book

L) Mentioned ways that people can help (i.e., gave out phone numbers for the Red Cross or charities, talked about the benefits of donating blood, etc.)

M) Asked students if their families and friends were physically affected

N) Other__ (write-in) 
Table 13.2 shows that some responses were more common in certain types of courses. For example, students reported that instructors led brief discussions about the attacks (Response $\mathrm{G}$ ) in studio classes more frequently than in other types of classes. In fact, brief discussions were reported in $49 \%$ of studio courses but in only $24 \%$ of traditional "discussion courses." One possible reason that discussions occurred with such high frequency in studio courses, most common in the fine arts (art, drama, architecture, etc.), is that the dean of the College of Fine Arts contacted all department chairs immediately following the attacks and encouraged faculty to be responsive to their students. To our knowledge, no other dean coordinated such efforts.

Likewise, certain responses were reported with less frequency for some classroom environments. For example, only $8 \%$ of the students in large lectures indicated that their instructors asked if friends or family had been affected by the attacks (Response M), whereas $10 \%-36 \%$ of the students reported that instructors asked about their families in other types of classes. By definition, these large lecture classes have enrollments of 50 students or more, and faculty may have felt unnatural or awkward posing such a personal question to large groups.

Helpfulness of responses. When an instructor did not mention the attacks at all, students did not rate the helpfulness of this nonresponse, so there is little quantitative data to report. Some students offered comments about their instructor's lack of response, and their comments conveyed frustration, disappointment, or apathy, but few conveyed that "doing nothing" was helpful or even appropriate. The following are some sample comments from students whose instructors made no mention of the terrorist attacks.

The instructor's ignoring of the events was terrible. People were panicking and he was acting like nothing happened.

-Female sophomore in a small lecture music class

My professor was a complete ${ }^{\star * \star}$ about the whole situation ... not only did he fail to try to do anything positive related to the attack, he made us come in on a Saturday morning to make up the class period that we missed due to classes being cancelled on September 11 .

-Male graduate student, small lecture business class

Very unhelpful. Showed little personal concern for the students. -Female senior, psychology discussion class

The instructor appeared not to take the event seriously enough. -Male graduate student, small lecture engineering class 
The instructor didn't mention the tragedy at all and surprisingly didn't give a nice historical or informational perspective: something I was hoping a history teacher would explain.

-Male first-year student, large lecture history class

None-no room for discussion at all.

-Female sophomore, large lecture chemistry class

The lack of activity was not detrimental. It didn't matter to me whether the professor talked about it or not.

-Male graduate student, project computer science course

When instructors did respond to the terrorist attacks, approximately two-thirds of the students evaluated the helpfulness of that response (66.4\%). The $33.6 \%$ of students who did not rate the helpfulness of their instructor's actions may have lacked a clear sense of what did or did not help them cope with the events, or they may have been fatigued by the length of the survey. Table 13.3 lists students' helpfulness ratings for 14 instructor-led activities.

As revealed in Table 13.3, many students found most responses very helpful, with the exception of Response B, which we shall return to momentarily. For the other 13 possible responses, $69 \%-100 \%$ of the respondents thought that the instructor's efforts to address the attacks were quite helpful, regardless of whether the instructor's response required relatively little effort, such as asking for one minute of silence (Response $\mathrm{C}$ ), or a great deal of effort and preparation, such as incorporating the event into the lesson plan or topics for the course (Response I). When instructors developed a class project related to the attacks, $100 \%$ of their students found such projects helpful, but the $\mathrm{N}$ for this response was small, with only two students (Response J). Some students indicated that their instructors' responses were not helpful, but at most, only $15 \%$ of the students found a response unhelpful or problematic (with the exception of Response B). The general conclusion from the students' perspective appears to be "do something, just about anything."

Several of the responses that students appreciated were consistent with the research on coping with highly stressful events. For example, $78 \%$ of the students found it very helpful when their instructor mentioned ways that people can support the rescue efforts: Instructors provided phone numbers for the Red Cross and other charities, informed students where they could donate blood, and the like. Taking action to address a problem is known as problemfocused coping and it is a relatively adaptive response to cataclysmic events, often more effective at reducing stress than simply venting or focusing on one's emotional reaction (Carver, Scheier, \& Weintraub, 1989). Accordingly, 
TABLE 13.3

Students' Perceptions of the Helpfulness of Instructor Responses

\begin{tabular}{|c|c|c|c|c|c|}
\hline \multirow[b]{2}{*}{$\begin{array}{c}\text { Instructor } \\
\text { Response }\end{array}$} & \multirow{2}{*}{$\begin{array}{c}\text { Number of } \\
\text { Reports } \\
\text { Which Rated } \\
\text { Helpfulness }\end{array}$} & \multicolumn{4}{|c|}{ Helpfulness Rating } \\
\hline & & $\begin{array}{c}\text { Uncertain or } \\
\text { N/A }\end{array}$ & Not Helpful & $\begin{array}{c}\text { Somewhat } \\
\text { Helpful }\end{array}$ & Very Helpful \\
\hline $\mathrm{A}$ & 174 & $11 \%$ & $7 \%$ & $11 \%$ & $71 \%$ \\
\hline B & 54 & $17 \%$ & $41 \%$ & $6 \%$ & $36 \%$ \\
\hline $\mathrm{C}$ & 32 & $3 \%$ & $10 \%$ & $7 \%$ & $80 \%$ \\
\hline $\mathrm{D}$ & 66 & $15 \%$ & $9 \%$ & $7 \%$ & $69 \%$ \\
\hline $\mathrm{E}$ & 150 & $8 \%$ & $7 \%$ & $16 \%$ & $69 \%$ \\
\hline $\mathbf{F}$ & 86 & $12 \%$ & $9 \%$ & $8 \%$ & $71 \%$ \\
\hline G & 140 & $9 \%$ & $13 \%$ & $9 \%$ & $69 \%$ \\
\hline $\mathrm{H}$ & 77 & $6 \%$ & $6 \%$ & $4 \%$ & $84 \%$ \\
\hline$I$ & 73 & $7 \%$ & $15 \%$ & $6 \%$ & $72 \%$ \\
\hline $\mathrm{J}$ & 2 & 0 & 0 & 0 & $100 \%$ \\
\hline $\mathrm{K}$ & 9 & $11 \%$ & $11 \%$ & 0 & $78 \%$ \\
\hline $\mathrm{L}$ & 45 & $14 \%$ & $4 \%$ & $4 \%$ & $78 \%$ \\
\hline$M$ & 115 & $15 \%$ & $8 \%$ & $8 \%$ & $69 \%$ \\
\hline $\mathrm{N}$ & 29 & $10 \%$ & $15 \%$ & $13 \%$ & $62 \%$ \\
\hline
\end{tabular}

\section{Key to Instructor Responses}

A) Acknowledged that the class needs to go on with the material but reassured the class that if students were too distressed to process the material that there would be other opportunities to review it down the road

B) Acknowledged that the attacks had occurred and said that the class needs to go on, with no mention of opportunities for review or extra help

C) One minute of silence

D) Mentioned counseling services

E) Excused students/offered extensions if assignnents were due

F) Offered to talk privately with anyone who might want to

G) Had a brief discussion in class

H) Devoted the whole first class after the attacks to discussion

I) Incorporated the event into the lesson plan/curriculum

J) Decided to do a project as a class (i.e., quilt, fence painting, etc.)

K) Read a passage from an inspirational book

L) Mentioned ways that people can help (i.e., gave out phone numbers for the Red Cross or charities, talked about the benefits of donating blood, etc.)

M) Asked students if their families and friends were physically affected

N) Other___ (write-in) 
one national study found that people who were indirectly affected by the $9 / 11$ attacks had lower levels of long-term stress when they took active, problem-focused approaches, which may explain why students benefited when instructors offered something concrete that they could do (Silver et al., 2002). Other potential responses addressed the cognitive load of a disaster. Recall that $69 \%$ of the students who were offered extensions or who were excused from class found this short-term break from their academic responsibilities to be very helpful. Although one might cynically interpret these numbers as students' general eagerness to postpone work whenever possible, cognitive and neuroscience research demonstrates that working memory capacity is reduced immediately following an acutely stressful experience (e.g., Arnsten, 1998; Newcomer et al., 1999). Since students would be less capable of learning new material in the initial wake of a collective tragedy, providing them with extensions or excusing them from class reduces their stress and allows them to produce work later that better reflects their normal abilities and study habits.

The one response that was clearly problematic, however, was Response $B$, which consisted of "acknowledging that the attacks had occurred and saying that the class needs to go on with no mention of opportunities for review or extra help." Relatively few students found this approach helpful (36\%), and an almost equal number found this response unhelpful (41\%). Some students explained that Response B was unhelpful because so little was done (e.g. "It wasn't really helpful because it was never really discussed"), and others found it unhelpful because students' needs were not addressed (e.g., "Very unhelpful-showed little personal concern for the students"). In contrast, most students found Response A very helpful (71\%), which, like Response B, emphasized moving on with the material, but unlike Response $B$, recognized students' needs by offering to review material later.

\section{Implications}

Previous research found that faculty generally felt uncertain about their responses to the events of September 11 (DiPietro, 2003). The current study offers some reassuring clarity as to how faculty and faculty developers can be most effective following a collective tragedy.

\section{Implications for Facully}

The first issue for faculty is deciding which events qualify as a collective crisis that should be addressed in the classroom. This was not one of our research questions, but we believe that several converging factors can help identify 
such events. Some events are likely to affect students because of their proximity (local campus events) or the sheer magnitude and scale (national events with wide media coverage). Other factors include a significant likelihood that the event will have a direct impact on students' families or social networks. Faculty should also consider the degree to which students are likely to identify with the victim(s) of the tragedy and feel like "vicarious victims" (which occurred with the $9 / 11$ terrorist attacks and could also occur for members of a group targeted by a hate crime) (Wayment, 2004). Finally, instructors can pay attention to a variety of situational cues. Are the students mobilizing on campus (e.g., through vigils)? Do faculty themselves find it hard to go back to class after the event? In all these cases, our results indicate that from the students' perspective, it is best to do something. Students often complained when faculty did not mention the attacks at all, and they expressed gratitude when faculty acknowledged that something awful had occurred. Beyond acknowledging a tragic event, faculty would be well advised to take the extra step of recognizing that students are distressed and to show some extra support, such as offering to grant extensions for students who request them.

It is perhaps a surprising relief to learn that an instructor's response need not be complicated, time intensive, or even personalized. Students are likely to appreciate responses that require relatively little effort, such as taking a minute of silence or offering to review material later in the course, so faculty should not feel pressed into redesigning their courses. Faculty responses that required high levels of effort were also viewed as helpful, so those who wish to use the lens of their discipline to examine the events surrounding a tragedy are encouraged to do so. A repeated issue that appeared in students' comments was that they appreciated an instructor who responded in a unique and humane way, so faculty should not feel pressured to homogenize their responses.

\section{Implications for Faculty Developers}

The results suggest that faculty developers can play several roles in the wake of a collective tragedy. First, faculty developers can provide resources and leadership to deans and department chairs. We know that one dean, the dean of the College of Fine Arts, contacted all of his department chairs to encourage faculty to address the attacks and support students. Professors teaching studio courses in the fine arts responded more strongly than most of their peers by leading more discussions, offering more extensions, offering to talk privately with more students, and so on. Although these studio instructors might have been just as proactive and compassionate without their dean's leadership, faculty developers should note that deans and department chairs 
are the nexus of faculty action. Connecting these key personnel with the findings from this study, along with online resources such as those at the University of Michigan (Center for Research on Learning and Teaching, 2004), empowers administrators to help their faculty respond more effectively.

A second implication for faculty developers is that if time and resources are limited, as they are likely to be following a tragedy, it would be strategic to focus on schools or departments that offer a greater number of project courses or large lecture courses. Our results indicate that faculty in these two types of courses were the least likely to mention the attacks, which would suggest that they are the most likely to benefit from guidance on how to respond. Although a full class discussion may not suit these courses, some of the quick, low-effort activities might work well.

The third role for faculty developers is to reassure faculty after the fact that their actions were probably helpful to students, even if it was not clear in class. As DiPietro (2003) noted, many faculty were still unclear about whether their responses were helpful several weeks later. The good news is that many students found most instructor responses, with the one noted exception, to be very helpful.

\section{Limitations}

There are limitations to this research. First, the data were collected several months after the tragic event, so students' memories might have been prone to error. The survey was intentionally delayed for several reasons. First, students' high stress levels immediately following the attacks would have impaired their ability to judge the effectiveness of an activity (Lazarus \& Lazarus, 1994; LeDoux, 1996; Liverant et al., 2004). Second, some instructors created final projects around the attacks, and students would not have completed such projects until the end of the course. Lastly, we were concerned that administering the survey too soon after the attacks might augment students' stress or emotional difficulty. Many students at this institution come from New York or New Jersey (22\% of the undergraduate students for 2001-2002), and students across campus experienced the events of $9 / 11$ quite personally.

A second limitation of this study is that the data were collected with respect to one tragic event that raised controversial issues of race, religion, cultural differences, and politics (to name a few), which could explain faculty hesitancy to mention the event in class. Faculty may be more likely to respond to other tragedies. However, as we observed with Hurricane Katrina and Matthew Shepard's death, traumatic events are often controversial. In that respect, faculty re- 
sponses to the events of September 11 are likely to shed some light on how faculty navigate their way through other highly charged collective tragedies.

\section{Conclusion}

A crisis raises anxiety and confusion throughout an institution, and faculty are likely to be unsure about what to do in the classroom. As faculty developers, we can provide suggestions and resources to administrators, and we can offer instructors a variety of approaches so they feel more empowered and less paralyzed. Faculty will be relieved to learn that most responses, even the simplest recognition that it will take time to adjust, are helpful to students.

\section{References}

American Psychiatric Association. (n.d.). Disasters: Mental health recommendations for students and colleges. Retrieved June 17, 2006, from http://healthyminds.org/ katrinatipsforcollege.cfm

Arnsten, A. F. T. (1998, June). The biology of being frazzled. Science, 280(5370), $1711-1712$.

Asmussen, K. J., \& Creswell, J. W. (1995, September/October). Campus response to a student gunman. Journal of Higher Education, 66(5), 575-596.

Carver, C. S., Scheier, M. F., \& Weintraub, J. K. (1989). Assessing coping strategies: A theoretically based approach. Journal of Personality and Social Psychology, 56(2), 267-283.

Center for Research on Learning and Teaching, University of Michigan. (2004). Publications and links. Retrieved June 17, 2006, from the University of Michigan, Center for Research on Learning and Teaching web site: www.crlt.umich.edu/ publinks/publinks.html

DiPietro, M. (2003). The day after: Faculty behavior in post-September 11, 2001, classes. In C. M. Wehlburg \& S. Chadwick-Blossey (Eds.), To improve the academy: Vol. 21. Resources for faculty, instructional, and organizational development (pp. 21-39). Bolton, MA: Anker.

Faculty Center for Excellence in Teaching, Western Kentucky University. (2000). Teaching and learning in a time of crisis. Retrieved June 17, 2006, from the Western Kentucky University, Faculty Center for Excellence in Teaching web site: www.wku.edu/teaching/booklets/crisis.html 
Farrell, E. F. (2001, December 21). Hedging against disaster. The Chronicle of Higher Education, p. A40.

Guterman, L. (2001, February 16). Student murdered in dormitory at Gallaudet University. The Chronicle of Higher Education, p.A49.

Honos-Webb, L., Sunwolf, Hart, S., \& Scalise, J. T. (2006). How to help after national catastrophes: Findings following 9/11. The Humanistic Psychologist, 34(1), 75-97.

Hurst, J. C. (1999, July/August). The Matthew Shepard tragedy: Management of a crisis. About Campus, 4(3), 5-11.

Larson, W. A. (Ed.). (1994). When crisis strikes on campus. Washington, DC: Council for Advancement and Support of Education.

Lazarus, R. S., \& Lazarus, B. N. (1994). Passion and reason: Making sense of our emotions. New York, NY: Oxford University Press.

LeDoux, J. (1996). The emotional brain: The mysterious underpinnings of emotional life. New York, NY: Touchstone.

Liverant, G. I., Hofmann, S. G., \& Litz, B. T. (2004, June). Coping and anxiety in college students after the September 11 th terrorist attacks. Anxiety, Stress, \& Coping, 17(2), 127-139.

Mangan, K.S. (2005, November 25). "Katrina" students are in every state. The Chronicle of Higher Education, p. A45.

Michigan State University Libraries. (2005). Hurricane Katrina: Research and resources. Retrieved June 17, 2006, from the Michigan State University Libraries web site: www.lib.msu.edu/libinstr/katrina.htm

Newcomer, J. W., Selke, G., Melson, A. K., Hershey, T., Craft, S., Richards, K., et al. (1999, June). Decreased memory performance in healthy humans induced by stress-level cortisol treatment. Archives of General Psychiatry, 56(6), 527-533.

Paine, C., \& Sprague, J. (2000). Crisis prevention and response: Is your school prepared? Oregon School Study Council Bulletin, 43(2), 1.

Rooney, M. (2002, November 8). Student kills three University of Arizona professors. The Chronicle of Higher Education, p. A12.

Siegel, D. (1994). Campuses respond to violent tragedy. Phoenix, AZ: American Council on Education/Oryx Press.

Silver, R. C., Holman, A., McIntosh, D. N., Poulin, M., \& Gil-Rivas, V. (2002, September). Nationwide longitudinal study of psychological responses to September 11. Journal of the American Medical Association, 288(10), 1235-1244. 
Wayment, H. A. (2004, April). It could have been me: Vicarious victims and disasterfocused distress. Personality and Social Psychology Bulletin, 30(4), 515-528.

Whiting, L. R., Tucker, M., \& Whaley, S. R. (2004, June). Level of preparedness for managing crisis communication on land grant campuses. Paper presented at the annual conference of the Association for Communication Excellence in Agriculture, Natural Resources, and Life and Human Sciences, Lake Tahoe, NV. 


\section{Appendix 13.1}

\section{Survey Questions for Activities Following the September 11, 2001, Terrorist Attacks}

1) Do you give Drs. Huston and DiPietro and their associates permission to present this work in written and oral form without further permission? Yes No

2) Gender: (1) Male (2) Female

3) College: Colleges listed

4) Major(s) or department in which you'll be getting a degree: Relevant departments listed for each college

5) Indicate your status as a student: (1) US citizen (2) International student

6) Class: (1) First-year student, (2) Sophomore, (3) Junior, (4) Senior, (5) Master's/ Graduate student

7) Please check the boxes of any university-wide activities you attended after 9/11: (1) Prayer/candlelight vigil (evening of the attacks), (2) A Time to Learn: Professors Explain the Crisis, (3) Peace rally, (4) Other-please explain.

8) How effective do you think the university-wide activity(ies) was (were)?

9) How many academic classes were you taking in September 2001?

10) Please think of one of the courses you were taking in September 2001. What department offers this course?

11) What type of class was this? (You may select multiple answers): (1) Discussion, (2) Small lecture ( $<50$ students), (3) Large lecture ( $>=50$ students), (4) Lab, (5) Studio, (6) Recitation, (7) Project course

12) Did the professor or TA mention the $9 / 11$ attacks in class or lead any activities related to them? Yes No

13) Please check the boxes next to anything that your professor did in this class that was related to $9 / 11$. This is easier if you read all of the options before you begin selecting them. You may check more than one.

See Key for Instructor Responses in Tables 13.2 and 13.3 for specific response items.

14) If you had a TA for this course, did the TA do anything in class to help the students? If so, what did he or she do? Same list of activities A-N as in Question 13.

15) How helpful or effective do you think the instructor's or the TA's activities were? If an activity was helpful, what made it helpful? If an activity was unhelpful, why didn't it help you?

Questions 10-15 were then repeated for each course that the student was taking in September 2001. 